\title{
Contribution to the Monitoring of Leptospira in Wild Animals (Hedgehog of Bouira District)
}

\section{Aouadi Nawal ${ }^{1 *}$, Mensah Tonyi Raouf ${ }^{2}$, Abbas Sadjia ${ }^{4},{\text { Bitam } \text { Idir }^{3} \text { and }}$ Arab Karim ${ }^{1}$}

${ }^{1}$ Department of Biology, VALCORE Research Laboratory, University of M'hamed Bougara Boumerdès, Algeria

${ }^{2}$ Ecole Supérieure des Techniques Biologiques de l'université de Lomé, Togo

${ }^{3}$ Higher School of Food Sciences and Agri-Food Industries (ESSAIA), El Harrach,

Algiers, Algeria, Aix Marseille Univ, IRD, VITROME, IHU Mediterranee Infection,

Marseille, France

${ }^{4}$ Department of biology, University of M'hamed Bougara, Algeria

*Corresponding Author: Aouadi Nawal, Department of Biology, VALCORE Research

Laboratory, University of M'hamed Bougara Boumerdès, Algeria.
Received: March 25, 2021

Published: April 27, 2021

(C) All rights are reserved by Aouadi Nawal., et al.

\section{Abstract}

Leptospirosis is an anthropozoonotique disease of worldwide distribution with tropical dominance. It is caused by a pathogenic bacterium Leptospira interrogans which her primary reservoirs are rodents that shed the bacteria in the urine. Leptospira is widespread in the environment (freshwater, moist soil, sludge...).

This study was carried out at Pasteur Institute of Algiers PIA's laboratory, the ecology of vector systems department in different regions of Bouira district focused on the detection of leptospira spp in different samples: blood, organs, and urine of wild-caught animals (hedgehogs).

After analysis of various samples (9 hedgehogs) in regions M'chedallah, Raffour, and Ahl- el -Ksar in 2012, we were able to isolate leptospira by the bacteriological test (culture of urine, liver, and kidney) $22.22 \%$ of positivity, Test of thermo- resistant antigen (33.33\% of positivity) and Microscopic-Agglutination-Test (0\%). These diagnostic approaches appear to be complementary Keywords: Leptospirosis; Anthropozoonosis; Hedgehog; Bacteriological Test; Serological Test; Environment

\section{Abbreviations}

TR test: Test of Thermo-Resistant Antigen/Macro-agglutination Test; MAT: Microscopic-Agglutination-Test; EMJH: Ellignyhausen, Mc Cullough, Johnson et Harris MEDIUM; DFM: Dark Field Microscopy

\section{Introduction}

Leptospirosis is a neglected anthropozoonosis disease of global distribution, contagious affecting animals and humans and caused by the spirochetal bacterium "Leptospira" $[1,2]$. 
The classification is based on criteria of pathogenicity and antigen recognition. These two parameters are used to distinguish pathogenic species, agent of Leptospirosis in humans and animals (L. interrogans) a commensal species (L. biflexa), found in the environment [3].

Leptospira interrogans in the wider sense includes all pathogenic Leptospira and thus subdivided into 64 genomospecies; more than 300 serovars [4-6].

A serogroup is defined as all strains bearing common epitopes on the outer membrane, inducing the production of agglutinating antibodies. These agglutinating antibodies are the basis of serological screening for infection [7]. The reservoirs of leptospirosis are especially wild rodents, a great number of animals could be a source of infection by Leptospira [3,8]. The polymorphism of the symptoms and the variety of affected organs, make the clinical diagnosis of leptospirosis very difficult [9]. Epidemiological cases most frequently reported are in acute forms, sub-acute and chronic. $\mathrm{Hu}$ mans can become infected by direct or indirect way [10] (Figure 1).

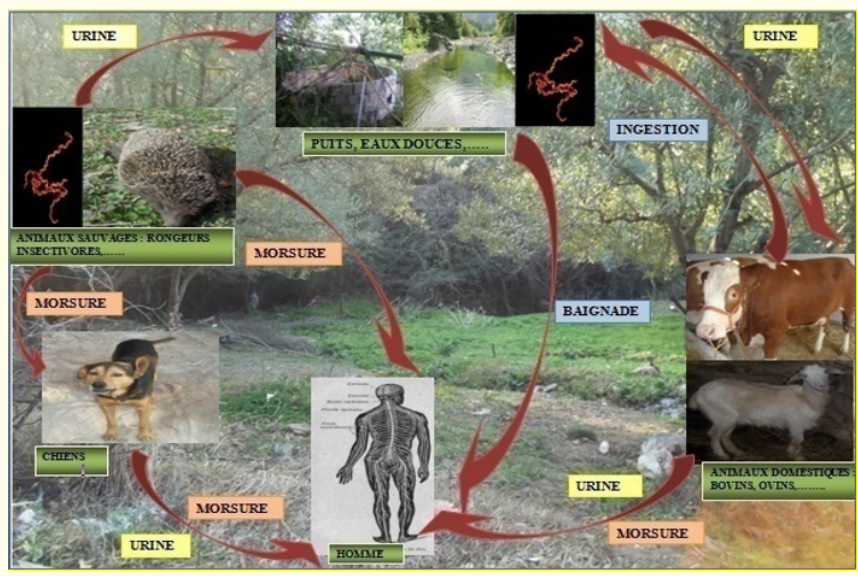

Figure 1: Contamination mode by Leptospira.

In Algeria, few studies in epidemiological, clinical and biological fields have been devoted to this zoonosis, even after the outbreaks of two cities in Algeria (Tizi-ouzou, Sétif) [11-13], the most recent study suggest that stray dogs are hosts for Leptospira spp [14].

\section{Objective of the Study}

The objective of our study is to evaluate the risk of transmitting Leptospira to humans by the hedgehog who is suggested may have a role in the epidemiology of tick-borne encephalitis (TBE), Borrelia spp, et Anaplasma phagocytophilum [15-17]. The diagnostic contribution of bacteriological and serological tests was evaluated.

\section{Materials and Methods}

Hedgehogs were captured between December 2011 (winter) and May 2012 (spring) using traps to catch wild animals or using a hunting dog. All collected samples were processed in the laboratory of Ecology vector systems department at Pasteur Institute of Algiers PIA (Annex Hamma).

\section{Collection of arthropods (ticks and fleas)}

- Ticks: Collecting ticks is done using a pointed tweezers. The technique is based on visual examination of the spines of hedgehogs by discarding the them for any visible ticks and remove them (Figure 2).

- $\quad$ Fleas: We have are collected by a direct remove using also a pointed tweezers, in a large basin of light color, more than $30 \mathrm{~cm}$ tall to prevent their escape (Figure 3).
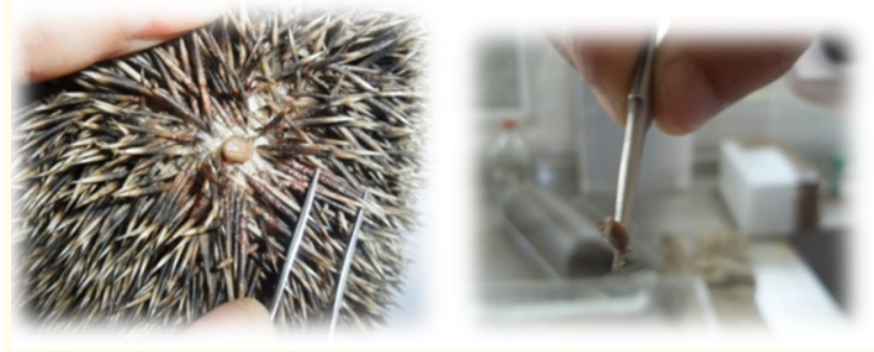

Figure 2: Ticks collection method.

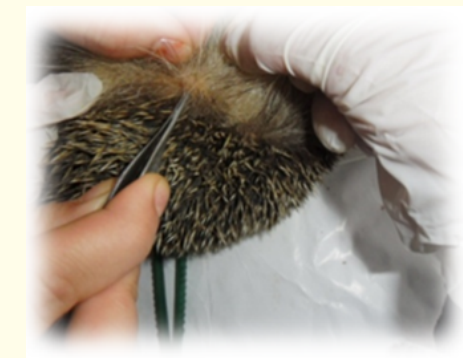

Figure 3: Fleas collection method. 
The collected Ticks and fleas are stored in tubes containing Ethanol $70^{\circ}$ to avoid dryness that weakens strongly the specimens. We mention the area where ticks and fleas were collected and the collection date, on each tube.

\section{Samples' collection}

We perform a cardiac puncture to collect blood in a sterile dry tube. This will allow us to do a serological study, after the death of the animal with Ether soaked cotton, we withdraw $0.5 \mathrm{ml}$ or more of urine than we retrieve the kidneys, the liver, and a total of 36 specimens were recuperated from 9 hedgehogs.

\section{Bacterial culture}

We proceed on direct reading of drop of urine with the dark field microscopy (DFM) to search for Leptospira, and then we inoculate the organs (kidneys and liver) in the EMJH medium followed by homogenization by the vortex, we Incubate at $29^{\circ} \mathrm{C}$ in the dark due to the sensitivity of this bacterium to light, the observations of the cultures are weekly and this on dark-field microscopy (magnification $\mathrm{x} 40$ ).

Microscopic examination of a drop is enough to recognize the germ by their mobility and morphology (thin filaments). A twomonth observation period is required before concluding the negativity of the culture.

\section{Test of thermo-resistant antigen}

It is a microscopic agglutination reaction on slide that uses a thermo-resistant antigen manufactured and marketed by Bio-Rad (France). On a clean slide, drop $35 \mu \mathrm{l}$ of pure serum to be tested with $35 \mu \mathrm{l}$ of a thermo-resistant antigen reactive then carefully mix the serum and the antigen by animating the blade of a rotary motion for about 4 minutes. The positive reaction is concluded by the observation of more or less large clusters on the periphery of serum, the absence of this agglutination suggest a negative result.

\section{Test of reference (MAT)}

MAT is a suitable tool for epidemiological surveys, it help determine the infection sarovars during outbreak [18]. It consists in searching agglutination between Antigen (Leptospira strain) and Antibogy (serum hedgehogs). The experiment consists of two parts: qualitative and quantitative MAT.

We execute a quantitative MAT to determine the serum titer of each of the concerned antigens, in the case of a positive reaction with the qualitative MAT [19].

\section{Molecular test}

It includes DNA extraction from kidneys samples, Verification of purity and the reliability of the extraction technique by simple electrophoresis without PCR amplification followed by PCR and finishes with a revelation of the DNA bands by a trans-illuminator. A total volume of $100 \mu$ of DNA was extracted from 9 kidney samples according to the manufacturer's recommendations (QIA amp de QIAGEN (QIAGEN- Germany). The primers sequences and fusion temperature of genes amplified by PCR are illustrated in table 1.

\begin{tabular}{|l|c|l|c|c|}
\hline Bacterium & $\begin{array}{c}\text { Gene (ampli- } \\
\text { con size) }\end{array}$ & Primers & Sequence & Tm \\
\hline Leptospira & $\begin{array}{c}16 \text { Srrs } 2 \\
\text { taille }: 542 \mathrm{pb}\end{array}$ & Lepto F & $\begin{array}{c}5^{\prime} \text { GCG-GCG-AAC- } \\
\text { GGG-TGA-CTA-A 3' }\end{array}$ & $54^{\circ} \mathrm{C}$ \\
\cline { 3 - 4 } & & Lepto R & $\begin{array}{c}5^{\prime} \text { GGA-AAG-TTA- } \\
\text { TCC-CAG-ACT-C 3' }\end{array}$ & \\
\hline
\end{tabular}

Table 1: Details of the targeted sequence (Invitrogen-France). Lepto F: Primer forward; Lepto R: Primer reverses.

\section{Results and Discussion}

The nine hedgehogs were captured in the fields and their surrounding are randomly selected. All the sampled hedgehogs belongs to Atelerix algirus ( 3 females sand 6 males). This study found that the hedgehog is a richly parasitized animal where 180 fleas and 130 ticks were counted in the three regions of Bouira district: Ahl el-Ksar, Raffour and Ilyithène cause they are a perfect hosts for arthropods (Table 2 and figure 4) [20]. The regions of Ahl-el- Ksar and Ilyithène were more parasitized than Raffour because both regions were characterized by a strong rurality, a major river system and the presence of various wild and domestic animals.

Direct observations of the urine of nine Hedgehogs are all negative. This result may be due to a premature urine collection rela- 


\begin{tabular}{|c|c|c|c|}
\hline $\begin{array}{c}\text { Hedgehog's } \\
\text { region }\end{array}$ & $\begin{array}{c}\text { Number of sampled } \\
\text { hedgehogs }\end{array}$ & $\begin{array}{c}\text { Ticks } \\
\text { number }\end{array}$ & Fleas number \\
\hline Ahl-el-ksar & 3 & 75 & 23 \\
\hline Raffour & 3 & 26 & 9 \\
\hline ilyithène & 3 & 29 & 148 \\
\hline Total & 9 & 130 & 180 \\
\hline
\end{tabular}

Table 2: The number of the collected arthropods.

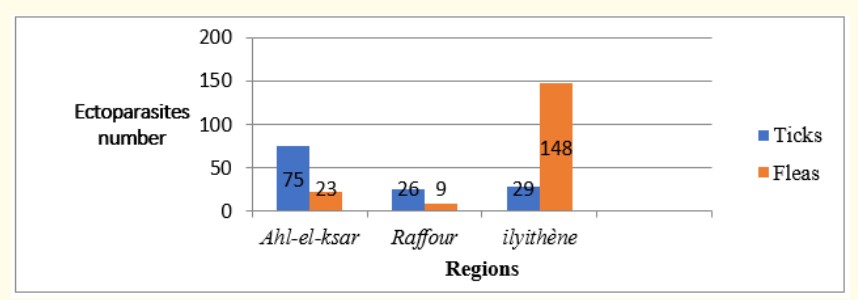

Figure 4: Distribution of ectoparasites compared to regions studied.

tive to the disease progression [21], or because the Leptospira are eliminated intermittently in urine and contaminate the external environment, or it is due to the acidity of urine $\mathrm{pH}$ measured in all urine samples to vary between 4.8 and 6.2 ).

These results do not prove the definitive absence of Leptospira because it takes two months to three of culture to confirm the presence of the latter [22]. Over the two months (8 weeks) of culture, we note the presence of different bacteria. The weekly reading of each culture takes place for two months from the $1^{\text {st }}$ week to $8^{\text {th }}$. This observation under dark field microscopy magnification $(G \times$ 40 ) helped see spirochetes form of long and very fine filaments and sometimes bacilli and coccobacilli from $5^{\text {th }}$ and $6^{\text {th }}$ week of kidney and liver culture whom belonged respectively to hedgehogs 7 and 8 ; the positivity rate is $22 \%$ on 09 hedgehogs, indicates the presence of Leptospira (Figure 5).

These results are consistent with those from France where they had 5 positive kidney cultures out of 26 samples [23].

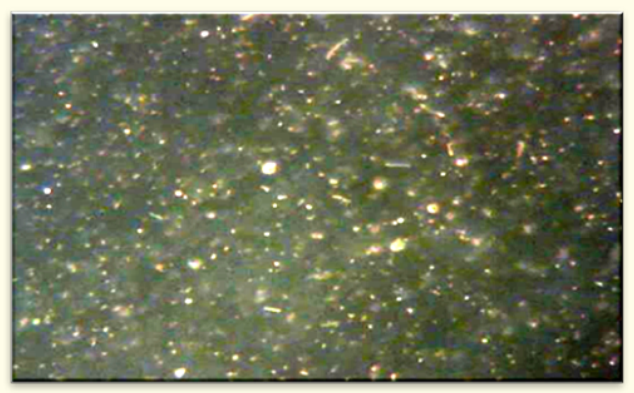

Figure 5: Spirochetes in kidney culture of hedgehog $\mathrm{n}^{\circ} 7$ seen by $\mathrm{DFM}(\mathrm{G} \times 40)$.

This low rate of positivity found is perhaps due to the filtrations we carried out during the cultures; also it could be regeneration time that the bacteria need after changing the medium, this unsure and time consuming technique is hardly reliable for an exact detection [24].

The positivity rate of $33.33 \%$ for the Macro-agglutination test (TR) does not seem very significant perspective of specificity (Table 3). In fact there is a rapid test for several common serogroups, his lack of sensitivity and specificity does make him a presumptive test [25], which makes it suitable for an accurate diagnosis [26]. Hence this result needs to be confirmed with the MAT test.

\begin{tabular}{|c|c|}
\hline Hedgehog's number & Result of TR \\
\hline 1 & Positive \\
\hline 2 & Negative \\
\hline 3 & Negative \\
\hline 4 & Positive \\
\hline 5 & Negative \\
\hline 6 & Negative \\
\hline 7 & Negative \\
\hline 8 & Negative \\
\hline 9 & Positive \\
\hline
\end{tabular}

Table 3: Results of macro-agglutination test. 
All the hedgehogs' sera were negative to the qualitative MAT (no agglutination) (Figure 6). However, it remains the most appropriate test for sero-epidemiological surveys. According to the WHO, the positivity threshold for the MAT reaction is $1 / 100$ [21].

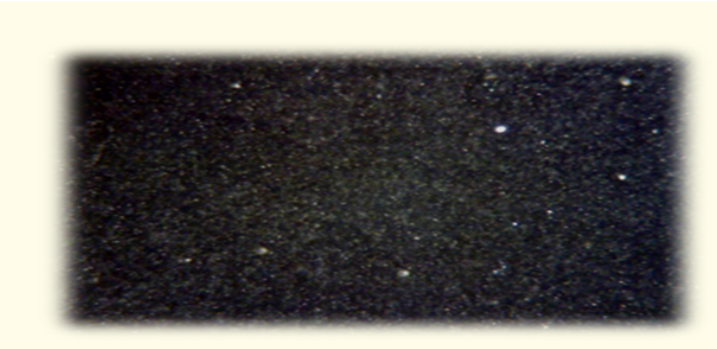

Figure 6: MAT qualitative of hedgehog's serum $N^{\circ} 4$ (with serogroup Australis) no agglutination.

According to Ayral., et al. [27] the hedgehog is a carrier of L. interrogans Australis, and one can assume that this insectivore is one of the main reservoirs. However, the absence of positive case of this research may be due to the early recovery of the animal serums, as the MAT to become positive 8-10 ${ }^{\text {th }}$ days after infection [24]. During the $1^{\text {st }}$ week, $2^{\text {nd }}$ to $4^{\text {th }}$ week of infection, MAT's sensibility recorded to be $41 \%, 96 \%$ respectively $[28,29]$. We should note that the source of water is treated by the leaders of these municipalities which can also prevent contamination of hedgehogs.

Despite the good quality and reliable DNA positive witness, this study could not get a result on the molecular diagnostic PCR, fault of a poor choice of hybridization temperature, Polymerase Chain Reaction is the most useful and effective tool for a rapid and successful detection of Leptospira, thanks to this technique a Chinese study reported the presence of this bacterium in hedgehogs' kidney tissues which confirm the role of hedgehogs as host reservoirs of Leptospira interrogans [30].

In general, from the positive results of cultures, we can speak of the presence of spirochetes in the tested animals. Serological examination (Macro-agglutination Test), also showed agglutination, synonymous with the presence of spirochetes without proving that these are Leptospira. The Micro-Agglutination Test which is a confirmatory test shows negative results, it can be explained by a less sensitive of this test in early stage of the disease [24]. Therefore, we deduce the absence of Leptospira in the tested hedgehogs, perhaps the positive cases it could be Treponema that has almost the same features as Leptospira.

These results may be due to the mismatch between the period of our research and the seasonal activity of the bacteria. According to the publication of Ward [31], there is a very marked seasonal peak of Leptospirosis from July to November associated with the rainfall season while our research was carried out from December to June $[32,33]$.

Similarly, regular rat eradication campaigns of the municipalities reduce the risk of proliferation of the bacteria in these regions, where the number of hedgehogs' analyzed samples remains inadequate and unrepresentative; this study could be enhanced by another approach by detecting of Leptospira spp in hedgehog's arthropods to confirm the role of host reservoir and vector of hedgehogs.

\section{Conclusion}

Leptospirosis is the most worldwide spread zoonosis. Potentially deadly, it evolves in an endemo- epidemic mode associated with weather events especially the rainy ones. This work carried out for six months at the Pasteur Institute of Algeria is an epidemiological approach to monitoring the spread of the disease in the one of Algerian provinces through animal reservoirs (hedgehogs) in the environment.

This study was done in the province of Bouira on the three areas is not an accurate reflection of the spread of the disease in it. However due to the severity of the disease and its evolutionary potential related to possible global warming, monitoring remains to be continued in the provinces at risk and also in others, given that the country is endemic for leptospirosis and human cases occur almost every year. 


\section{Acknowledgements}

The authors wish to thank Mrs Amara-khorba for her contribution and professional assistance during the study as well as we gratefully thank all the member of Pasteur institute of Algiers annex Hamma especially department of ecology of vectors systems.

\section{Conflict of Interest}

None.

\section{Bibliography}

1. J Koko., et al. "Leptospirosis in children in Libreville : First case report, a difficult diagnosis L eptospirose de l' enfant à Libreville : difficultés diagnostiques, à propos d ' un cas". Bulletin de la Société de pathologie exotique 95 (2002): 394-396.

2. C Goarant. "Leptospirosis : risk factors and management challenges in developing countries". Research and Reports in Tropical Medicine 7 (2016): 49-62.

3. P N Levett. “Leptospirosis Leptospirosis”. Clinical Microbiology Reviews 14.2 (2001): 296-326.

4. N Philip., et al. "Leptospira interrogans and Leptospira kirschneri are the dominant Leptospira species causing human leptospirosis in Central Malaysia". PLOS Neglected Tropical Diseases 265 (2020): 1-14.

5. J Guglielmini., et al. "Genus-wide Leptospira core genome multilocus sequence typing for strain taxonomy and global surveillance". PLOS Neglected Tropical Diseases 13.4 (2019): 1-23.

6. C Coudert., et al. "La leptospirose humaine en polynésie Francaise: Aspects épidémiologiques, cliniques et bactériologiques". Tropical Medicine 67.2 (2007): 137-144.

7. H Mohammed and B Rekia. "Diagnostic de la Leptospirose Humaine: Méthodes de Détection de la Maladie Diagnosis of Human Leptospirosis : Methods for Detection of Disease Diagnostic clinique Diagnostic non spécifique". Les Technol. Lab 6 (2011).
8. M Haraji., et al. "Forme ictérique de la Leptospirose Humaine : présentation d ' un cas à El Jadida, Maroc". Les Technol. laboraoire (2011).

9. D Laurent., et al. "La leptospirose: Étude clinique et microbiologique à propos de 11 cas". Médecine et Maladies Infectieuses 34.1 (2004): 42-47.

10. A R Bharti., et al. "Leptospirosis: A zoonotic disease of global importance". Lancet Infectious Diseases 3.12 (2003): 757-771.

11. M Afiri., et al. "Aspects épidémiologiques, cliniques et évolutifs de 173 cas de leptospirose". Bulletin de la Société de pathologie exotique (2013).

12. M Afiri., et al. "Renal manifestations of leptospirosis: 88 cases". Médecine et Santé Tropicales 23.2 (2013): 234-235.

13. S Derdour., et al. "Prevalence of the main infectious causes of abortion in dairy cattle in Algeria". Journal of Veterinary Research 61.3 (2017): 337-343.

14. S Zaidi., et al. "Urinary shedding of pathogenic Leptospira in stray dogs and cats , Algiers : A prospective study". (2018): $1-11$.

15. J Skuballa., et al. "European hedgehogs as hosts for Borrelia spp., Germany 8”. Emerging Infectious Diseases 13.6 (2007).

16. J Skuballa., et al. "Molecular detection of Anaplasma phagocytophilum in the European hedgehog (Erinaceus europaeus) and its ticks". Vector-Borne and Zoonotic Dissease 10.10 (2010): 1055-1057.

17. J Skuballa., et al. "Occurrence of different Borrelia burgdorferi sensu lato genospecies including B. afzelii, B. bavariensis, and B. spielmanii in hedgehogs (Erinaceus spp.) in Europe". Ticks and Tick-borne Diseases 3.1 (2012): 8-13.

18. R Niloofa., et al. "Diagnosis of leptospirosis: Comparison between microscopic agglutination test, IgM-ELISA and IgM rapid immunochromatography test". PLoS One 10.6 (2015). 
19. PN Levett. "Usefulness of serologic analysis as a predictor of the infecting serovar in patients with severe leptospirosis". Clinical Infectious Diseases 36.4 (2003): 447-452.

20. G Földvári., et al. "Ticks and the city: Ectoparasites of the Northern white-breasted hedgehog (Erinaceus roumanicus) in an urban park". Ticks and Tick-borne Disesase 2.4 (2011): 231-234.

21. S Obertin. "Etude clinique et microbiologique à propos de onze cas de leptospirose observés au C.H.U de Nancy entre 1996 et 2003". UHP - Université Henri Poincaré (2006).

22. T Gaillard., et al. "Moyens biologiques et stratégie diagnostique de la leptospirose neuroméningée. À propos d'un cas". Revue de Médecine Interne 30.4 (2009): 361-364.

23. F Aviat., et al. "La leptospirose, zoonose de loisir et zoonose professionnelle: rôle des rongeurs et de l'eau”. Epidémiol santé anim 45 (2004) : 55-60.

24. S V Budihal and K Perwez. "Leptospirosis diagnosis: Competancy of various laboratory tests". Journal of Clinical and Diagnostic Research 8.1 (2014): 199-202.

25. M Afiri., et al. "Leptospirosis epidemic: 48 cases". Médecine et Santé Tropicales 23.2 (2013): 234.

26. PN Levett. "Leptospirosis". Clinical Microbiology Reviews 14.2 (2001): 296-326.

27. F Ayral., et al. "Hedgehogs and mustelid species: Major carriers of pathogenic Leptospira, a survey in 28 animal species in France (20122015)". PLoS One 11.9 (2016).

28. S C Sehgal., et al. "LEPTO Dipstick: A rapid and simple method for serodiagnosis of acute leptospirosis". Transactions of The Royal Society of Tropical Medicine and Hygiene 93.2 (1999): 161-164.

29. D Musso and B La Scola. "Laboratory diagnosis of leptospirosis: A challenge". Journal of Microbiology, Immunology and Infection 46.4 (2013): 245-252.

30. XJ Ma., et al. "Detection of Leptospira interrogans in Hedgehogs from Central China". Vector-Borne and Zoonotic Disease 20.6 (2020): 427-431.
31. M P Ward. "Seasonality of canine leptospirosis in the United States and Canada and its association with rainfall". Preventive Veterinary Medicine 56.3 (2002): 203-213.

32. S Pawar., et al. "Seasonality of leptospirosis and its association with rainfall and humidity in Ratnagiri, Maharashtra". International Journal of Research in Health and Allied Sciences 7.1 (2018): 37.

33. K P Hacker., et al. "Influence of rainfall on leptospira infection and disease in a tropical urban setting, Brazil". Emerging Infectious Diseases 26.2 (2020): 311-314.

\section{Assets from publication with us}

- Prompt Acknowledgement after receiving the article

- Thorough Double blinded peer review

- Rapid Publication

- Issue of Publication Certificate

- High visibility of your Published work

Website: www.actascientific.com/

Submit Article: www.actascientific.com/submission.php

Email us: editor@actascientific.com

Contact us: +919182824667 